\title{
Development and Characterization of Ulvan Polysaccharides-Based Hydrogel Films for Potential Wound Dressing Applications
}

\author{
Evi Sulastri iD ${ }^{1,2}$ \\ Muhammad Sulaiman Zubair ${ }^{2}$ \\ Ronny Lesmana ${ }^{3}$ \\ Ahmed Fouad Abdelwahab \\ Mohammed $^{4}$ \\ Nasrul Wathoni (iD) \\ 'Department of Pharmaceutics and \\ Pharmaceutical Technology, Faculty of \\ Pharmacy, Universitas Padjadjaran, \\ Sumedang, 45363, Indonesia; ${ }^{2}$ Department \\ of Pharmacy, Faculty of Mathematics and \\ Natural Sciences, Universitas Tadulako, Palu, \\ 94I I9, Indonesia; ${ }^{3}$ Department of \\ Biomedical Science, Faculty of Medicine, \\ Universitas Padjadjaran, Sumedang, 45363, \\ Indonesia; ${ }^{4}$ Department of Pharmaceutics, \\ Faculty of Pharmacy, Minia University, Minia, \\ 61519, Egypt
}

Background: Ulvan is a natural polymer and type of sulfated polysaccharides from green seaweed that could have potential as a candidate for wound dressing material based on the support of its biopolymer characteristics such as antioxidant and antimicrobial activities.

Objective: In this study, we developed and prepared three different hydrogel films to explore the potency of ulvan for wound dressing application.

Methods: Ulvan hydrogel films were prepared by the facile method through ionic crosslinking with boric acid and added glycerol as a plasticizer. The films were evaluated in regard to swelling degree, water vapor transmission (WVTR), Fourier transform infrared (FTIR), powder $\mathrm{x}$-ray diffractometry (P-XRD), scanning electron microscopy (SEM), mechanical properties, thermogravimetric analysis (TGA), differential scanning calorimetry (DSC), antimicrobial, and antioxidant activity.

Results: The hydrogel films showed that the different concentration of ulvan in the formula affects the characteristics of the hydrogel film. The higher the concentration of ulvan in UHF, the higher the value of viscosity $(201 \pm 13.45$ to $689 \pm 62.23$ cps for UHF5 to UHF10), swelling degree ( $82 \%$ to $130 \%$ for UHF5 to UHF10 at $1 \mathrm{~h})$, moisture content $(24 \% \pm 1.94 \%$ to $18.4 \% \pm 0.51$ for UHF5 to UHF10), and the WVTR were obtained in the range 1856 $2590 \mathrm{~g} / \mathrm{m}^{2} / 24 \mathrm{~h}$. Meanwhile, the SEM showed porous hydrogel film. Besides, all hydrogel films can reduce hydroxyl radicals and inhibit gram-positive and negative bacteria (Staphylococcus aureus, Pseudomonas aeruginosa, Escherichia coli, and Streptococcus epidermidis).

Conclusion: The swelling behavior and WVTR of these films are great and could have potential as a wound dressing biomaterial, supported by their antimicrobial and antioxidant properties.

Keywords: ulvan, hydrogel films, wound dressing, antioxidant, antimicrobial

\section{Introduction}

Optimal wound care management can be obtained by employing materials that have pharmacological activity and a role in wound treatment, such as antimicrobial and antioxidant agents. ${ }^{1-7}$ Wounds are very easily contaminated by microbes, resulting in infection, which can further prolong the inflammatory phase and the wound healing process. ${ }^{8,9}$ Currently, biomaterials from natural polysaccharides are widely used for this purpose, such as alginates, carrageenan, starch, xyloglucan, and others. These materials have been broadly used in wound treatment including wound dressings because of their non-carcinogenic nature, low toxicity, and high
Correspondence: Nasrul Wathoni Department of Pharmaceutics and Pharmaceutical Technology, Faculty of

Pharmacy, Universitas Padjadjaran,

Sumedang, 45363, Indonesia

Tel +6228428888883510

Fax +622842888888

Email nasrul@unpad.ac.id 
biocompatibility, and their structural similarity to the extracellular matrix (ECM) so that they can be easily recognized by cells. ${ }^{10-12}$ Alongside, they have abundant sources of raw materials in nature. ${ }^{13-16}$

Ulvan is a natural polymer derived from green seaweed that can be found on various coastlines in Indonesia such as in the province of West Nusa Tenggara, East Nusa Tenggara, Sulawesi, Maluku, Riau, Sumatra, Java, and Bali. $^{17,18}$ In fact, Indonesia is the second-largest seaweedproducing country in the world. Nevertheless, the pharmaceutical use of this water-soluble polysaccharide is still limited concerning the number of studies, especially its development in pharmaceutical preparations. ${ }^{19-22}$

Ulvan consists of uronic acid including glucuronic acid and/or iduronic with various sugars such as rhamnose, xylose, arabinose, and glucose. This composition may vary depending on the species, ecophysiology, extraction, and purification process. ${ }^{23-25}$ The presence of a rare sugar class in the backbone (rhamnose sulfate sugar and iduronic acid) makes this material a unique polysaccharide. Rhamnose is usually found in bacteria and plants and is rare in animals. Polysaccharides that are rich in rhamnose compounds show stimulation by cell proliferation and collagen biosynthesis. ${ }^{26-28}$ Likewise, iduronic acid, which has never been identified in other types of seaweed along with glucuronic acid, has structural similarity to mammalian glycosaminoglycans (GAG) found in human skin ECMs such as chondroitin sulfate, heparan sulfate, dermatan sulfate, and hyaluronic acid. GAG plays an important role in cellular regulation associated with wound treatment. ${ }^{29,30}$

Hydrogel film wound dressings have been shown to accelerate wound healing by providing a moist environment for the wound and its ability to absorb wound exudate. $^{31}$ The hydrogel mechanism of Ulvan occurs through ionic crosslinking with boric acid. The gelation mechanism associates the hydroxyl group from Ulvan with borate, which can involve rhamnose and uronic acid. Those interactions are supported by the hydrogen bonding association. Alternatively, it can also involve ionic interactions between either the carboxylic group of uronic acid and/or sulfate with borate through divalent cation due to the acidic moieties of Ulvan. ${ }^{32,33}$ These interactions are physical crosslinking, which is advantageous in regard to safety compared to chemical crosslinking because we can avoid the cytotoxicity caused by the unreacted chemical crosslinker. $^{34,35}$ In addition, glycerol was added as a plasticizer to the hydrogel film formula. Plasticizers are the most important additive and almost always present in film formulations, especially films made from natural materials to improve the flexibility, elasticity, processability, and mechanical properties of polymers. ${ }^{36,37}$ Glycerol is a polyol compound containing three hydroxyl groups in its molecule, when interspaced in the polysaccharide network, the distance between the polysaccharide chains increases, and direct interactions are reduced resulting in an increase in the elongation, ${ }^{38,39}$ thickness, moisture content, solubility, and smooth surface structure. ${ }^{40,41}$

In this work, we report the preparation and characterization of hydrogel films of Ulvan to be used as a dressing for wound healing applications.

\section{Materials and Methods Materials}

All chemical reagents for ulvan isolation such as ethanol, sodium hydroxide $(\mathrm{NaOH})$, hydrochloric acid $(\mathrm{HCl})$, activated charcoal, cellulase, and protease were analytically graded and purchased from Sigma-Aldrich. Green algae Ulva lactuca Linn. were collected in JanuaryFebruary 2020 from Banggai Laut Coast in Central Sulawesi province, Indonesia (Latitude: $1^{\circ} 36^{\prime} 12.1^{\prime \prime} \mathrm{S}$, Longitude: $\left.123^{\circ} 29^{\prime} 32.4^{\prime \prime} \mathrm{E}\right)$ for isolation of Ulvan. The sample occurs naturally on the rocky shore. The authenticity of the algae (Number: B-808/IPK.2/IF.07/X/2020) was confirmed by Dr. Ir. Augy Syahailatua, M.Sc. and Tri Handayani, S.Si., M.Si. from Indonesian Institute of Sciences and voucher specimens (Number: 022/ UN28.1.28/PSF/KP/2020) was deposited in Pharmacognosy Laboratory, Department of Pharmacy, Faculty of Mathematics and Natural Sciences, Universitas Tadulako. Boric acid, glycerol, and deionized water were obtained from Sigma-Aldrich.

\section{Isolation of Ulvan from Ulva lactuca Linn}

The fresh sample was washed in seawater then placed in a plastic bag. At the laboratory, the samples were washed again with distilled water and dried in an oven $\left(35^{\circ} \mathrm{C}, 72 \mathrm{~h}\right)$. The dried alga was milled in a grinder for $5 \mathrm{~min}$. The sample was stored until used in a dry container and dark place at room temperature. The extraction of ulvan follows the methods by Alves et $\mathrm{al}^{42}$ and Costa et $\mathrm{al}^{43}$ with slight modifications. One kilogram of dried algae powder was soaked in $96 \%$ ethanol $(400 \mathrm{~mL})$ to remove lipids and coloring matter for $3 \times 24 \mathrm{~h}$ at room temperature, every $24 \mathrm{~h}$ the solvent is replaced. The residual was mixed with $20 \mathrm{~L}$ of distilled 
water, adjusted to $\mathrm{pH} 2(\mathrm{HCl})$. Extraction was carried out at $85^{\circ} \mathrm{C}$ for $1 \mathrm{~h}$ at $90 \mathrm{rpm}$ using a water bath. The supernatant was filtered and then neutralized by the addition of 1 $\mathrm{M}$ sodium hydroxide $(\mathrm{NaOH})$ to adjust at $\mathrm{pH} 7$. Furthermore, polyphenyl, chlorophyll, and aroma of extracts were removed by adsorption on activated charcoal. The extracts were hydrolyzed with the cellulase enzyme (700 U/ g) and protease $(0.8 \mathrm{U} / \mathrm{g})$ to remove starch and protein (respectively). After that, the aqueous extracts were filtered and then centrifuged at $3000 \mathrm{rpm}$ for $30 \mathrm{~min}$. The solution was dried using a freeze dryer to obtain crude Ulvan. The crude ulvan was washed with $96 \%$ ethanol, centrifuged, and dried. The dried crude was dissolved in deionized water and centrifuged (5000 rpm, $20 \mathrm{~min}$ ). The supernatant was collected and freeze-dried to obtain Ulvan polysaccharides.

\section{Preparation of Ulvan Hydrogel Films}

Ulvan $(5 \%, 7.5 \%$, and $10 \%)$ was dissolved in deionized water. Then, boric acid was added as a crosslinker $(0.1 \%)$ and glycerol $(2 \%)$ as a plasticizer. The mixture is homogenized using a magnetic stirrer at $50^{\circ} \mathrm{C}$ for $15 \mathrm{~min}$ and then continued at room temperature for $45 \mathrm{~min}$ to form a homogeneous hydrogel. After the homogenization was completed, $10 \mathrm{~mL}$ volume of the mixture was poured into Petri dishes (diameter: $5 \mathrm{~cm}$ ) and dried at $45^{\circ} \mathrm{C}$ for $48 \mathrm{~h}$ to form Ulvan Hydrogel Film (UHF). UHF is removed from the mold and stored in a closed container for further evaluation.

\section{Evaluation of Ulvan Hydrogel Films Organoleptic, pH, and Viscosity Test}

The organoleptic examination was performed using the human visual appearance of the UHF at room temperature. Meanwhile, the $\mathrm{pH}$ determination was carried out by a $\mathrm{pH}$ meter. One percent of each sample was diluted with distilled water $(20 \mathrm{~mL})$ in a glass beaker $(25 \mathrm{~mL})$. The $\mathrm{pH}$ should be in the range of 4.5-6.5. The viscosity of samples was determined by a viscometer (Brookfield).

\section{Weight and Thickness}

The weights of hydrogel films (UHF) were measured using an analytical balance, and the thicknesses were measured using Vernier calipers. The UHF sample test was repeated at five different positions of the film with $0.001 \mathrm{~mm}$ of accuracy. The result was expressed as a mean of the measurements \pm standard deviation (SD).

\section{Mechanical Strength}

Tensile strength (TS) and elongation at break (EB) were measured using a Tensile Tester (Zwick Roell) based on ASTM standard method D1822 at a stretching rate of $10 \mathrm{~mm} / \mathrm{min}$ and preload of $0.05 \mathrm{MPa}$ and UHF were cut to $7 \times 5 \mathrm{~cm} .{ }^{44}$ The TS and EB values were calculated using the following equations:

$$
\begin{aligned}
& \text { TS }\left(\mathrm{N} / \mathrm{mm}^{2}\right)=\frac{\text { Force at break }(\mathrm{N})}{\text { Initial cross sectional area }\left(\mathrm{mm}^{2}\right)} \\
& \mathrm{EB}(\%)=\frac{\text { Increase in lenght }(\mathrm{mm}) \text { at break }}{\text { Initial film lenght }(\mathrm{mm})} \times 100
\end{aligned}
$$

\section{Moisture Content}

UHF $(2 \times 2 \mathrm{~cm})$ was placed in a porcelain cup and dried in the oven at $90^{\circ} \mathrm{C}$ for $24 \mathrm{~h}$. The moisture content was calculated using the following equation:

$$
\text { Moisture content }=\frac{m 1-m 2}{m 2} \times 100
$$

Where $\mathrm{m} 1$ and $\mathrm{m} 2$ are the initial and final weight of UHF, respectively.

\section{Swelling Degree}

The hydrogel film $(1.5 \times 1.5 \mathrm{~cm})$ was immersed in phosphate buffer saline solution $(25 \mathrm{~mL}$ ) at $\mathrm{pH} 7.4$ (room temperature). After 1, 4, and $6 \mathrm{~h}$, the sample was slowly removed from the buffer solution, and the excess buffer on the surface of the sample is dried with filter paper and then the sample was weighed again. The swelling degree was calculated by the following equation:

$\%$ swelling degree $=(\mathrm{Ws}-\mathrm{Wd}) / \mathrm{Wd} \times 100$

where Ws is the weight of swollen film at a certain time, and $\mathrm{Wd}$ is the weight of the first film (dried film).

\section{WVTR (Water Vapor Transmission)}

Five-gram anhydrous calcium chloride was placed into a weighted bottle. The film was fitted and placed at the top of the bottle and tied with thread, and then the bottle was placed into a desiccator $(75 \% \mathrm{RH}$ at room temperature). The WVTR of the samples was calculated according to the following equation:

\section{$\mathrm{WVT}=\mathrm{W} / \mathrm{S}$}

where $\mathrm{W}$ is the weight of the film at $24 \mathrm{~h}, \mathrm{~S}$ is the area of the film $\left(\mathrm{m}^{2}\right)$ 


\section{SEM (Scanning Electron Microscopy)}

\section{Analysis}

The surface morphology of the film was observed by Jeol JSM-IT300 with an operating voltage of $20 \mathrm{kV}$. The UHF samples were placed at the sample holder and coated with gold-palladium for $10 \mathrm{~s}$. The SEM micrographs were taken at distances between 8.4 and $13.4 \mathrm{~mm}$ at $\mathrm{x} 100$ and $\times 5000$ magnification. The images were captured in three different areas of the films to evaluate the consistency of the microstructures.

\section{FTIR Analysis}

The infrared absorption characteristics of Ulvan and UHF were studied by FTIR spectroscopy (IR-Prestige-21, Shimadzu, Japan). The sample was prepared in potassium bromide disks. The spectra were produced with wavenumbers ranging from $4000 \mathrm{~cm}^{-1}$ to $400 \mathrm{~cm}^{-1}$ at a resolution of $4 \mathrm{~cm}^{-1}$.

\section{PXRD (Powder X-Ray Diffraction)}

The PXRD pattern of Ulvan and UHF samples was measured using a diffractometer operating at $40 \mathrm{kV}$ and $40 \mathrm{Ma}$ with $\mathrm{Cu}$ radiation. Diffractograms were taken between $6^{\circ}$ and $70^{\circ}(2 \theta)$ at a rate of $1.20^{\circ} / \mathrm{min}(2 \theta)$ and with a step size of $0.020^{\circ}(2 \theta)$.

\section{TGA (Thermogravimetric Analysis) and DSC (Differential Scanning Calorimetry)}

The TGA and DSC analysis aim to determine the thermal properties of the hydrogel film. The analysis was carried out by taking Ulvan and UHF samples in experimental conditions at a heating speed of $5^{\circ} \mathrm{C}$ per minute (with a range of $-50-250^{\circ} \mathrm{C}$ ) using a DSC/TGA instrument analyzer (LINSEIS-STA PT 1600). The sample was placed in an open platinum crucible, and an empty container was used as a reference. Thermal analysis was carried out under a stream of dry nitrogen gas $\left(30 \mathrm{~mL}\right.$ per minute). ${ }^{42}$

\section{Antioxidant Activity}

The hydroxyl radical scavenging effect was determined according to the method reported by $\mathrm{Xu}$ et $\mathrm{al}^{45}$ with slight modification. Briefly, the film solutions were prepared by dissolving film in distilled water. Each UHF sample is made in five different concentration $(10,20,30,40$, and $50 \mathrm{mg} / \mathrm{mL}$ ); then, $1 \mathrm{~mL}$ of various concentrations was mixed with $\mathrm{FeSO}_{4}(1 \mathrm{~mL}, 6 \mathrm{mM}), \mathrm{H}_{2} \mathrm{O}_{2}(0.5 \mathrm{~mL}, 6$ $\mathrm{mM})$, and salicylic acid-ethanol $(0.5 \mathrm{~mL}, 6 \mathrm{mM})$. The mixtures were incubated at $37^{\circ} \mathrm{C}$ for $30 \mathrm{~min}$. Then absorbance was measured at $510 \mathrm{~nm}$. Distilled water was used as the control group. The absorbance of the control group was measured as A0 (water instead of sample solution); Ai was the result for the sample and $\mathrm{Aj}$ was the absorbance for samples with water replacing the $\mathrm{H}_{2} \mathrm{O}_{2}$. The hydroxyl radical scavenging activity was calculated by the following equation:

Hydroxyl radical scavenging activity $(\%)=[\mathrm{A} 0-$ $(\mathrm{Ai}-\mathrm{Aj})] / \mathrm{A} 0 \times 100 \%$

\section{Antimicrobial Activity}

The antibacterial activity of the samples was tested against Staphylococcus aureus (ATCC ${ }^{\circledR}$ 25923),Pseudomonas aeruginosa (ATCC ${ }^{\circledR}$ 9027),Escherichia coli $\left(\right.$ ATCC $\left.^{\circledR} 35218\right)$, and Streptococcus epidermidis (ATCC ${ }^{\circledR}$ 12228) conducted agar diffusion method using Mueller Hinton Agar (MHA) as media. The medium was dissolved at $100^{\circ} \mathrm{C}$, cooled to $45-$ $48^{\circ} \mathrm{C}$ then poured into Petri dishes $(25 \mathrm{~mL})$. In Mueller Hinton Agar (MHA), the suspension of each bacterial strain was prepared at a concentration of $1 \times 10^{8} \mathrm{CFU}$ (colony forming unit) $/ \mathrm{mL}$ (equivalent to $0.5 \mathrm{McFarland}$ standard) and $100 \mu \mathrm{L}$ of each suspension was mixed with the MHA media in Petri dishes. After medium solidification, the paper disk containing UHF samples was placed on the agar plates (each disk was dripped with $5 \mu \mathrm{L}$ each sample UHF). The plates were then incubated for $24 \mathrm{~h}$ at $37^{\circ} \mathrm{C}$, and zones of inhibition were measured around the samples.

\section{Statistical Analysis}

The data were presented as a mean of \pm SD for each result. The statistical analysis of the data was performed using the one-way analysis of variance (ANOVA) and comparisons between two means through Tukey's test. The statistical significance is considered for a $\mathrm{p}<0.05$.

\section{Results and Discussion}

\section{Pre-Formulation}

Ulvan hydrogel formation occurs through an ionic crosslinking reaction with boric acid and its preparation can be seen in Figure 1. Generally, crosslinking occurs through the utilization of ionic molecules to create bridges in polymer networks. Furthermore, the addition of glycerol to the Ulvan hydrogel film formula was intended to obtain a flexible film and enhancing the film's molecular mobility. ${ }^{46}$ The concentration of glycerol added must be optimal to maximize its function as a plasticizer. In this study, a $2 \%$ glycerol concentration was 


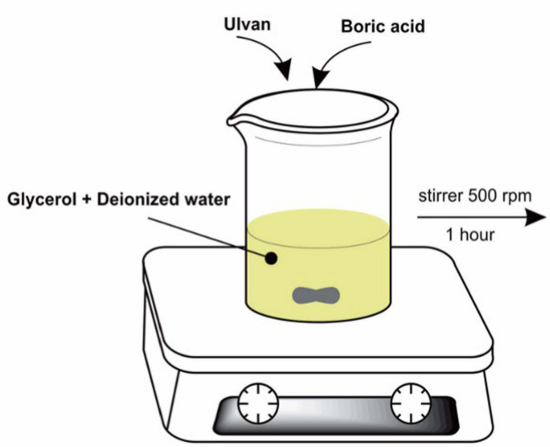

Figure I Scheme of UHF preparation.

used because a concentration less than that caused the film to be too brittle/broken, while a higher concentration caused the film to stick and be difficult to remove from the mold. This is in line with its high water-binding ability, reducing interactions between biopolymer molecules and increasing the solubility of polymers in water. ${ }^{40}$ The formulations of three hydrogel films with various Ulvan polymers namely $5 \%, 7.5 \%$, and $10 \%$ were carried out to see their effect on the characterization of the preparation and ensure its potential as a wound dressing.

\section{Organoleptic, Homogeneity, $\mathrm{pH}$, Viscosity Test}

The organoleptic evaluation showed that the three Ulvan hydrogel films were yellow-green where the higher the Ulvan concentration, the darker the color of the films (Figure 2A). Meanwhile, the $\mathrm{pH}$ of the three preparations was $6.34 \pm 0.37-7.5 \pm 0.53$ (Figure $2 \mathrm{~B}$ ). The $\mathrm{pH}$ value of the preparation is expected to be in the skin $\mathrm{pH}$ range so that it does not cause any irritations during their usage. The higher

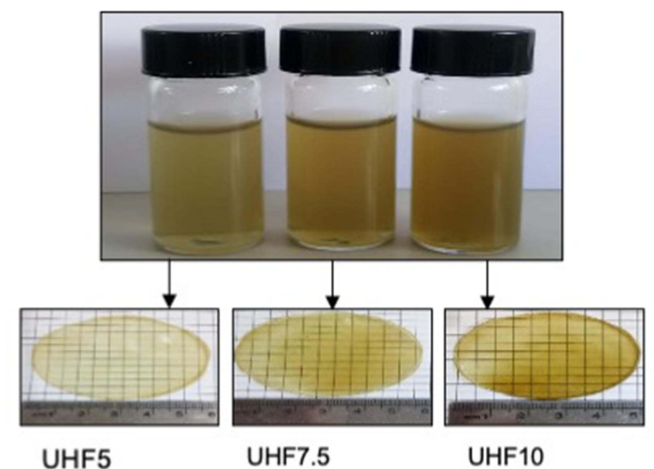

A
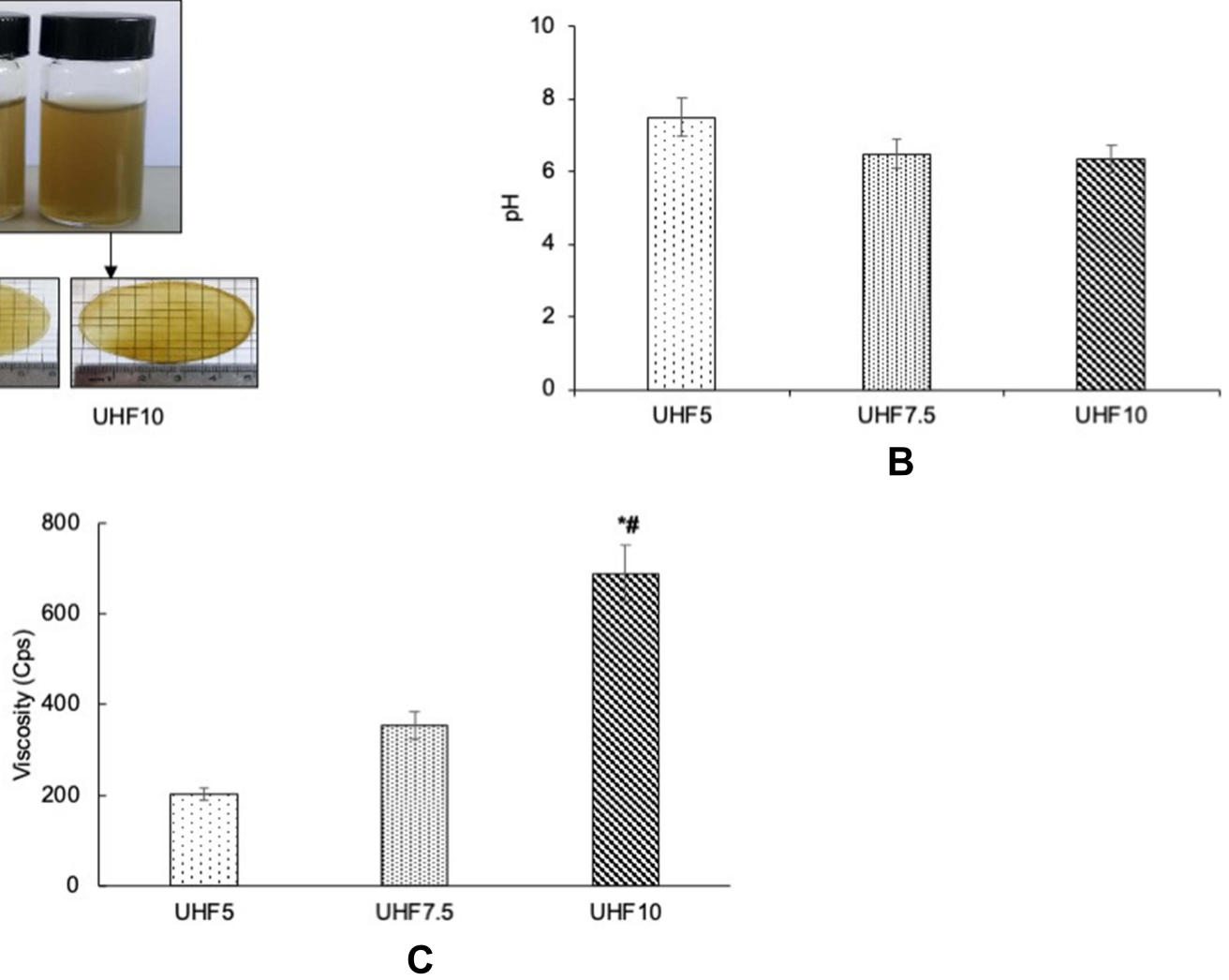

Figure 2 Characterization of UHF: organoleptic $(\mathbf{A}), \mathrm{pH}(\mathbf{B})$, viscosity $(\mathbf{C})$. Each value represents the mean $\pm \mathrm{SD}$ of three experiments. ${ }^{2}<0.05$, compared to the UHF 5. ${ }^{\#} \mathrm{p}<0.05$, compared to the UHF 7.5. 
the polymer concentration, the higher the viscosity of the preparation, where the viscosity values of the three preparations were $201 \pm 13.45,353.68 \pm 29.57$, and $689 \pm 62.23$ for UHF5, UHF7.5, and UHF10, respectively (Figure 2C). This viscosity value is related to the ability of Ulvan to expand in water and produce a 3-dimensional structure.

\section{Swelling Degree, Moisture Content, and Water Vapor Transmission (WVTR)}

After drying for $24 \mathrm{~h}$, the UHF retains moisture of $24 \%$ $\pm 1.94,19 \% \pm 0.66,18.4 \% \pm 0.51$ for UHF5, UHF7.5, and UHF10, respectively (Figure 3A). This characteristic is important because as a candidate biomaterial for wound dressing, hydrogel film preparations must be able to retain moisture in their structure throughout the application to accelerate wound healing.

The WVTR characteristic is also a very crucial property for wound dressings, which is related to its ability to provide a moist environment and gas exchange in the wound. The results in Figure 3B show that UHF5 $\left(2590 \pm 76.54 \mathrm{~g} / \mathrm{m}^{2} /\right.$ $24 \mathrm{~h}$ ) had the greatest WVTR value compared to UHF7.5 and UHF10 $\left(2518 \pm 175.168 \mathrm{~g} / \mathrm{m}^{2} / 24 \mathrm{~h}\right.$ and $1856 \pm 59.65 \mathrm{~g} / \mathrm{m}^{2} /$ 24h). Plasticizer can increase moisture diffusivity through polymer structure by increasing interchain distance between polymer chains. Hence, speed up the WVTR. ${ }^{46}$ However, the value is not significantly different $(p>0.05)$ from UHF7.5, and all three preparations still qualify WVTR for first-degree burns $\left(279 \mathrm{~g} / \mathrm{m}^{2} / 24 \mathrm{~h}\right)$ and for granulation wounds $\left(5138 \mathrm{~g} / \mathrm{m}^{2} / 24 \mathrm{~h}\right){ }^{47}$ Also, all hydrogel films can withstand drying and rehydration, which is very important in accelerating the wound healing process.

The swelling ability of the hydrogel film is one of the important characteristics in assessing the potential of the film as a wound dressing to promote healing, including its suitability as a drug delivery system for wound treatment. Figure 3C shows that UHF10 expands by $130 \%$ higher in the first hour than UHF 5 and UHF 7.5 which is $82 \%$ and $93.57 \%$, respectively. Furthermore, at sixth hours, UHF 7.5 and UHF 10 continued to increase its expansion up to $147.8 \%$ and $189 \%$, while for UHF5 the value could not be measured because the film became soluble in water (Figure 3C). As we have already mentioned, the physically crosslinked hydrogel films rapidly dissolve when immersed in water or physiological media than the chemical crosslinked hydrogel films. ${ }^{15}$ The degree of swelling of this hydrogel film is related to its ability to absorb exudate in
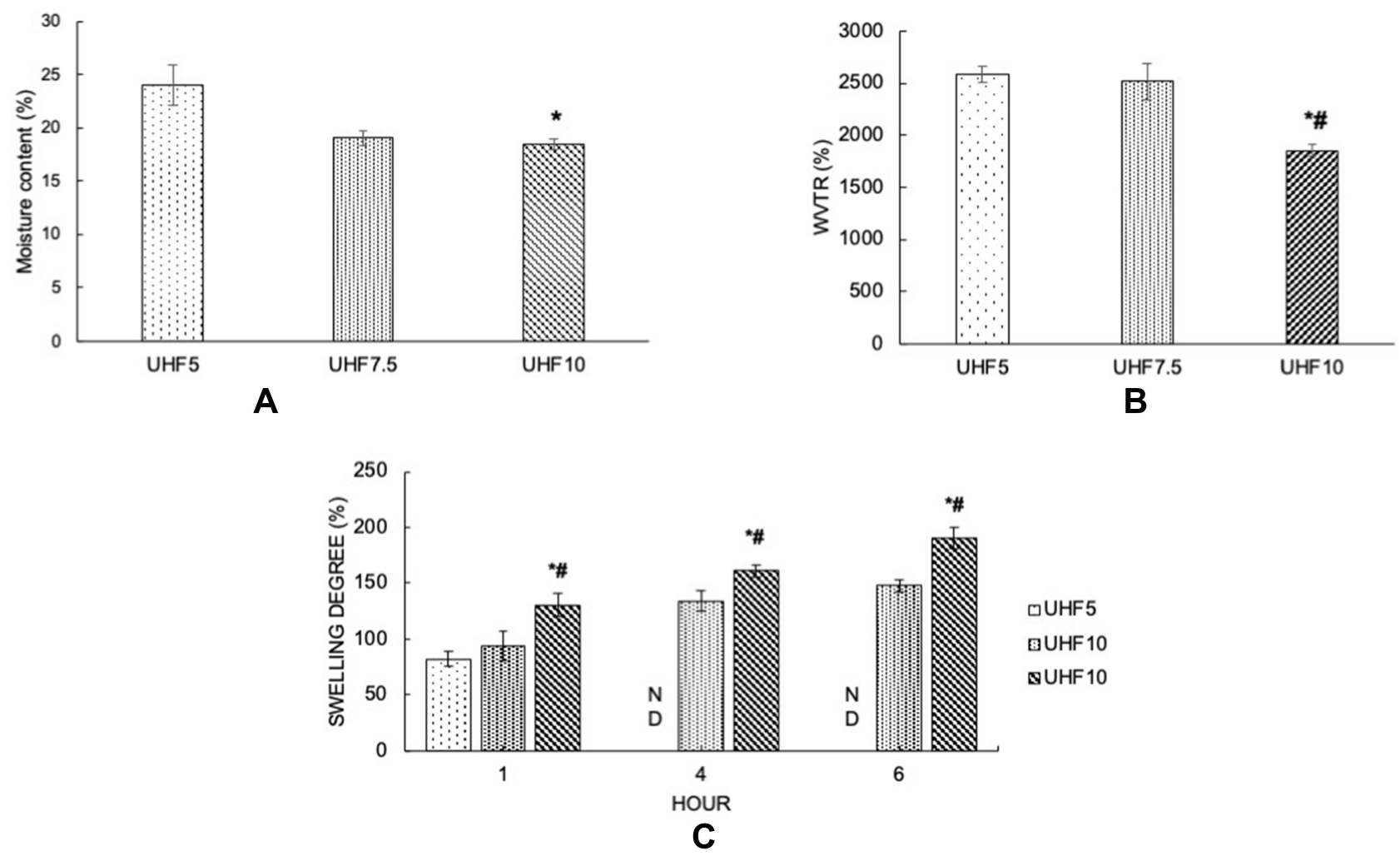

Figure 3 (A). Water content; (B). The water vapor transmission (WVTR); and (C). The swelling degree of UHF formula. Each value represents the mean \pm SD of three experiments. ${ }^{*} \mathrm{p}<0.05$, compared to the UHF 5 . ${ }^{\#} \mathrm{p}<0.05$, compared to the UHF 7.5. 
the wound area. In comparison, Pansara et $\mathrm{al}^{48}$ have prepared films for wound healing with chitosan. The swelling degree of the films was in the range of $53.17-267 \%$. Meanwhile, the WVTR value was in the range 2024.43-2111.22 gm.m ${ }^{-2} / 24$ $\mathrm{h}$. The result indicated that the higher the chitosan concentration in the film, the higher the swelling degree.

\section{Weight, Thickness, and Mechanical Strength}

The weight and thickness of produced hydrogel films can be seen in Figure 4A and B. It is observed that the Ulvan concentration affects the film weight and thickness. The higher the polymer concentration, the thicker and heavier the hydrogel films are. Film weight increased from 0.65 \pm 0.05 to $1.25 \pm 0.08$ (UHF5 to UHF10) with increasing ulvan concentration in the hydrogel films. The film thickness increased from $0.42 \pm 0.04 \mathrm{~mm}$ to $0.49 \pm 0.08 \mathrm{~mm}$ (approximately $16.67 \%$ ) for the UHF5 to UHF 7.5 formula and increased to $0.69 \pm 0.004 \mathrm{~mm}$ (approximately $40.82 \%$ ) for the UHF7.5 to UHF 10 formula. This is certainly proportional to the thickness. The film weight increased from 0.65 $\pm 0.05 \mathrm{~g}$ to $0.869 \pm 0.05 \mathrm{~g}$ (approximately $37.28 \%$ ) for the UHF5 to UHF 7.5 formula and increased to $1.25 \pm 0.09$

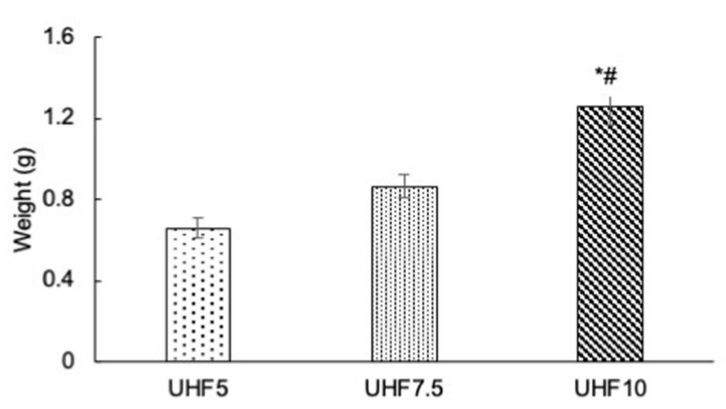

A (approximately $36.82 \%$ ) for the UHF7.5 to UHF 10 formula. Similarly, result by Üstündağ Okur et $\mathrm{al}^{49}$ reported that the thickness of films prepared from natural polymers (chitosan and sodium alginate) in the range $0.306-0.841 \mathrm{~mm}$ is acceptable for wound dressing application.

Mechanical properties play an important role in wound dressing applications related to film integrity and tissue growth. Our study shows that increasing polymer concentration is directly proportional to higher tensile strength and elongation break as well as improved mechanical properties of the UHF formula. In addition, the mechanical properties of the UHF formula increased with the increase in weight and thickness. The tensile strength values of the three formulas are $0.58 \pm 0.16-2.62 \pm 1.02 \mathrm{~N} / \mathrm{mm}^{2}$ and the percent elongation break of the three formulas is $9.53 \pm 0.81-17.66$ $\pm 0.58 \%$ (Figure $4 \mathrm{C}$ ). The recommended tensile strength value of wound dressing is $>1 \mathrm{~N} / \mathrm{mm}^{2}$ and elongation break is $>10 \%{ }^{48,49}$ Thus, according to the result, UHF10 showed better mechanical properties than another formula. Generally, polymers from a natural source, have a weakness in poor mechanical properties. Also, material with the porous structure is well known

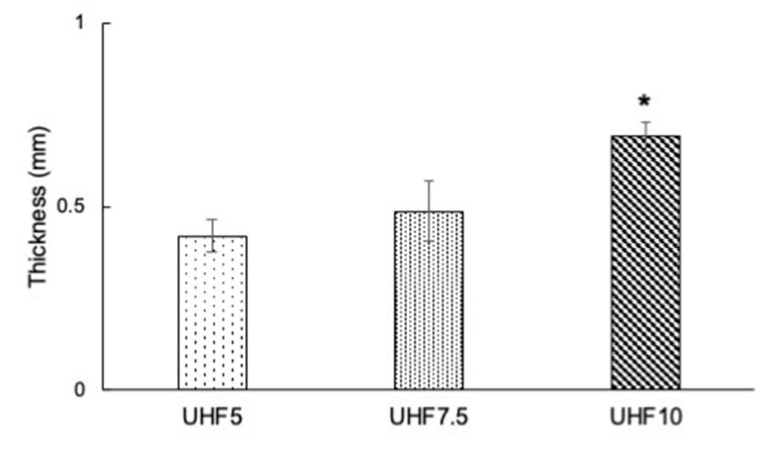

B

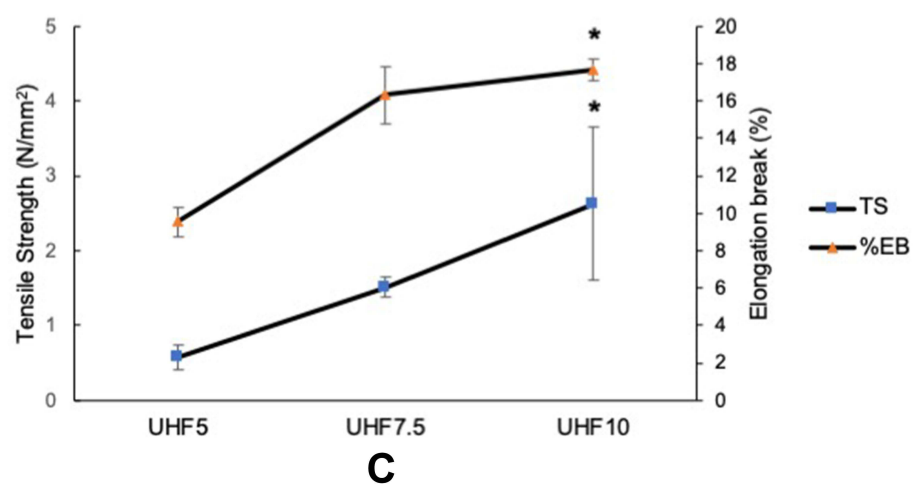

Figure 4 Characterization of UHF: weight (A); thickness (B); and mechanical strength (C). Each value represents the mean \pm SD of three experiments. * ${ }^{*}<0.05$, compared to the UHF 5. ${ }_{p}<0.05$, compared to the UHF 7.5. 
to have weak mechanical strength. ${ }^{50}$ As compared to our work, Pansara et $\mathrm{al}^{48}$ reported that the TS and EB of chitosan wound dressing films in their study were 1.10 $1.87 \mathrm{~N} / \mathrm{mm} 2$ and $10.56-14.44 \%$, respectively.

\section{SEM}

The surface morphologies of all UHF preparations look porous and regular. The porous structure of UHF causes good swelling ability and will be useful for supporting bioactive agents in the hydrogel structure and regulating their release. ${ }^{51}$ The porous structure of hydrogel films is also beneficial for absorbing a large amount of exudate in the wound. The incorporation of glycerol as a plasticizer into the film seems to affect the morphological structure of the film. Interestingly, Figure 5 shows that UHF5 and UHF10 have larger pore structures than UHF7.5 which is smoother and more homogeneous. The polymer-plasticizer ratio is thought to influence this. In this case, the ratio of Ulvan-glycerol (7.5:2) resulted in a smoother and more homogeneous surface structure.

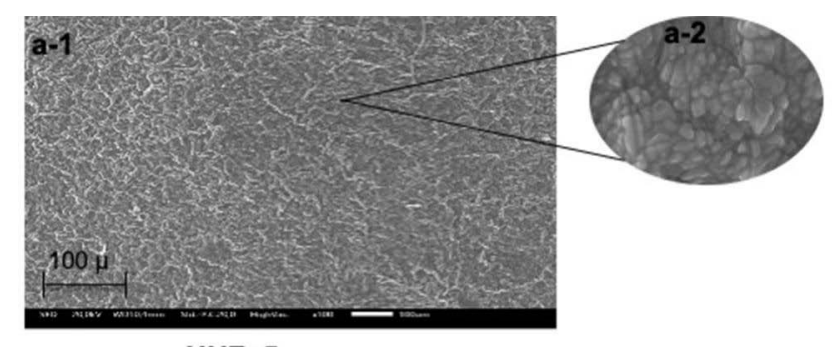

UHF 5

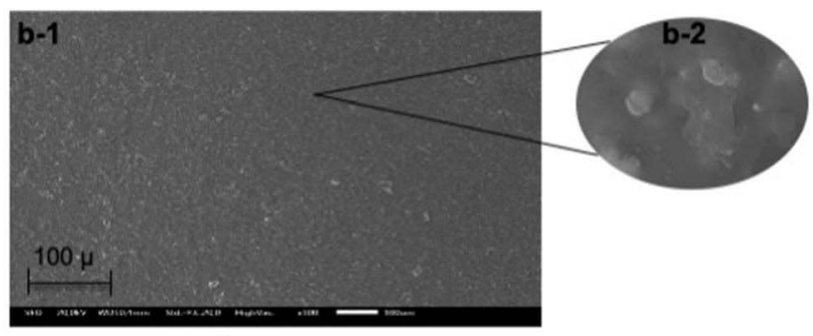

UHF 7.5

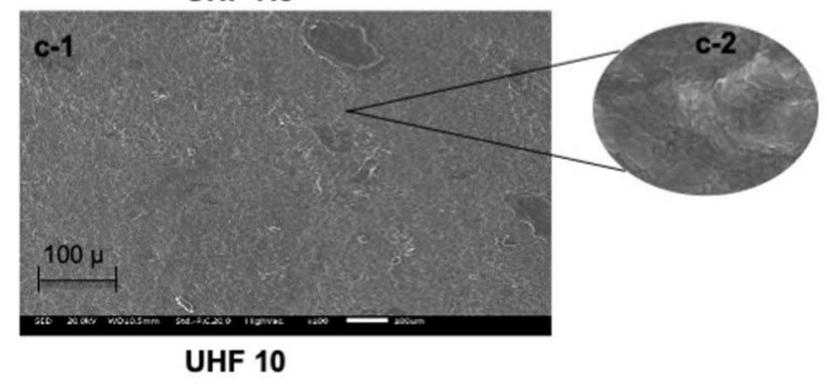

Figure 5 SEM images of UHF, taken at 100x magnifica tion (al-cl) and at 5000x magnification (a2-c2).

\section{FTIR Analysis}

FTIR spectroscopy can be used for the approximate identification of polysaccharides in materials when combined with chemical analysis. The FTIR spectra of UHF5, UHF7.5, and UHF10 compared with Ulvan are illustrated in Figure 6, the spectrums were similar, implying that the formulation of hydrogel films does not damage the main chain structure of Ulvan. FTIR spectra of the Ulvan show many of the characteristic peaks for this polysaccharide. The typical Ulvan peak was carboxyl groups in the uronic acid moieties, ${ }^{24,25}$ and it shows two characteristic signals: one symmetric stretching at $1643 \mathrm{~cm}^{-1}$ and confirmed at 1637, 1627, and $1654 \mathrm{~cm}^{-1}$ (UHF5, UHF7.5, and UHF10) for $\mathrm{C}=\mathrm{O}$ and one asymmetric stretching at 1433 for Ulvan and confirmed at 1425, 1427, and $1431 \mathrm{~cm}^{-1}$ (UHF5, UHF7.5, and UHF10) for $\mathrm{C}=\mathrm{O}$. Also, the small peak at $852 \mathrm{~cm}^{-1}$ was $\mathrm{C}-\mathrm{O}-\mathrm{S}$, which is characteristic of the $\beta$ glycoside bond in Ulvan moieties, which is an indication of the presence of polysaccharides and a similar peak confirmed in UHF5, UHF7.5, and UHF10 at 850, 850, and $848 \mathrm{~cm}^{-1}$, respectively. The peak at $1259 \mathrm{~cm}^{-1}$ in Ulvan corresponds to $\mathrm{S}=\mathrm{O}$ stretching of sulfate groups and is confirmed in UHF5, UHF7.5, and UHF10 at 1259, 1261 , and $1265 \mathrm{~cm}^{-1}$, respectively. The peak at $792 \mathrm{~cm}^{-1}$ in Ulvan corresponds to C-O-S stretching, suggesting the presence of sulfate groups and confirmed in UHF5, UHF7.5, and UHF10 at 792, 792, and $790 \mathrm{~cm}^{-1}$, respectively. Those groups are usually abundant in Ulvan. ${ }^{42,52}$

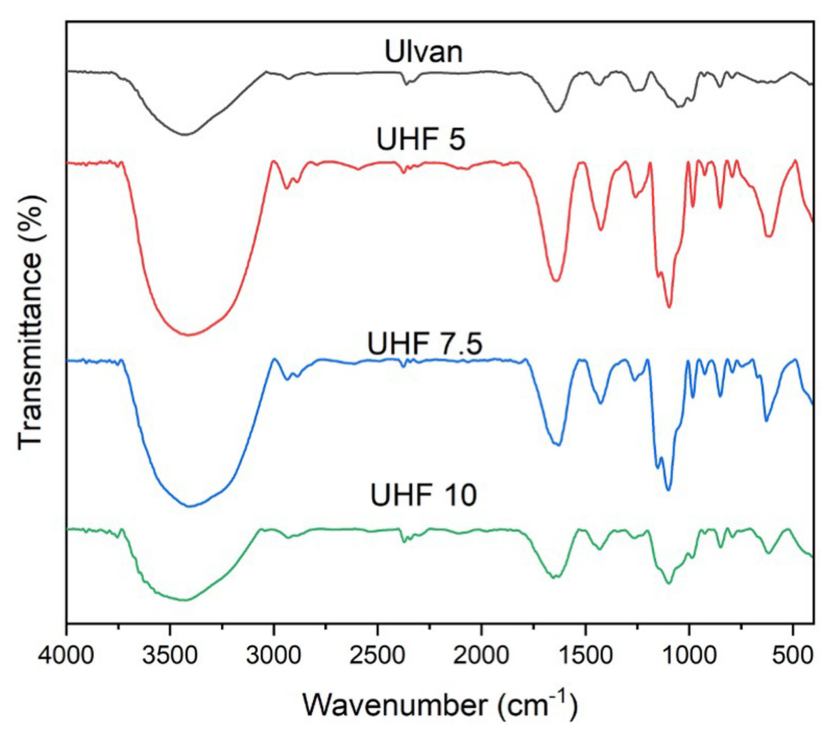

Figure 6 The Spectrum FTIR of UHF formula. 


\section{P-XRD}

The X-ray diffractograms of the ulvan showed sharp peaks at $2 \theta=32^{\circ}$ and $45^{\circ}$, which attributed to the crystal structure. ${ }^{40}$ A similar pattern is still observed in UHF7.5 and UHF10 but the $2 \theta$ degree little changed to $31^{\circ}$ and $44^{\circ}$, respectively. Meanwhile, the peak intensities for both UHF7.5 and UHF10 altered and significantly decreased compared with ulvan pattern (Figure 7). This may be influenced by crosslinking with boric acid and the addition of glycerol, which causes the polysaccharide to be more in an amorphous structure. For UHF5, the $32^{\circ}$ peak is still seen but has very low intensity. Meanwhile, the $45^{\circ}$ peak has disappeared. Result indicates that hydrogels and film-forming processes like mixing and drying could alter the crystallinity of ulvan polysaccharides. In addition, the mobility of polymer chains in ulvan structure with the addition of glycerol can also change the crystallinity of ulvan in UHF formulas. The results were in agreement with the work of Dash et al, ${ }^{53}$ which found that a diffraction pattern of ulvan sharp peak in scaffold was observed at $32^{\circ} 2 \theta$.

\section{TGA/DSC}

The result of the TGA and DSC analysis of UHF and Ulvan are reported in Figure 8A-D. For DSC analysis, all three formulas exhibited two stages of endothermic peaks and one exothermic peak. The first stage of degradation showed a broad endothermic peak (at $40-190^{\circ} \mathrm{C}$ ) for UHF5, (at $50-165^{\circ} \mathrm{C}$ ) for UHF7.5, and (at 70-190 ${ }^{\circ} \mathrm{C}$ ) for UHF10 refers to the elimination caused by the adsorption of water and the second stage is main degradation and involves decomposition of the sugars on Ulvan moieties (around $210^{\circ} \mathrm{C}$ ). Accordingly, the thermal stability of Ulvan is ensured until $190^{\circ} \mathrm{C}$. It could be a result of breaking the $\mathrm{C}-\mathrm{H}$ bonds and $\mathrm{C}-\mathrm{O}-\mathrm{C}$ glycoside bonds. ${ }^{50}$ An exothermic peak appearing at around $230^{\circ} \mathrm{C}$ in all formulas is attributed to the degradation of ulvan. The confirmed result of ulvan degradation and UHF is shown in the results of the TGA analysis. The weight loss continues to occur at around $130^{\circ} \mathrm{C}$ until approximately $210^{\circ} \mathrm{C}$.

Based on the DSC and TGA analysis of ulvan and UHF formula, the first and second-stage degradation of all UHF formulas was lower compared to the native Ulvan (at 50$160^{\circ} \mathrm{C}$ and $210^{\circ} \mathrm{C}$, respectively). This could be due to the effect of crosslinking of ulvan with boric acid and the addition of glycerol as a plasticizer, which could reduce the intermolecular interaction between polymer chains. ${ }^{40,54}$

\section{Antioxidant Activity}

All formulas show inhibition against free radicals. The higher the concentration of Ulvan in the formula, the higher the antioxidant activity of UHF. Ulvan polysaccharides could chelate $\mathrm{Fe}^{2+}$ in a dose-dependent manner in the formulation of films. This is indicated by the pattern UHF10 $>$ UHF7.5 $>$ UHF5 as shown by the $\mathrm{OH}$ radical scavenging ability of the film's

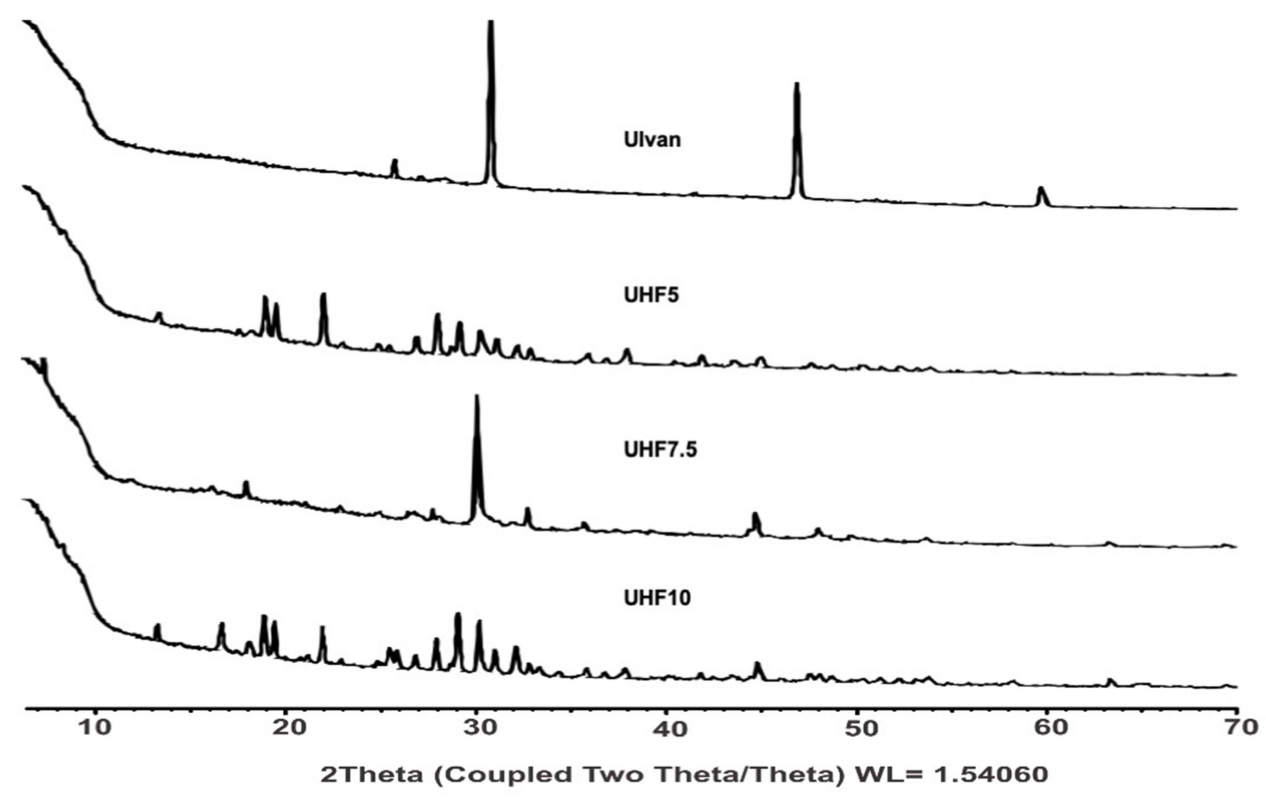

Figure 7 The XRD pattern of UHF formula. 

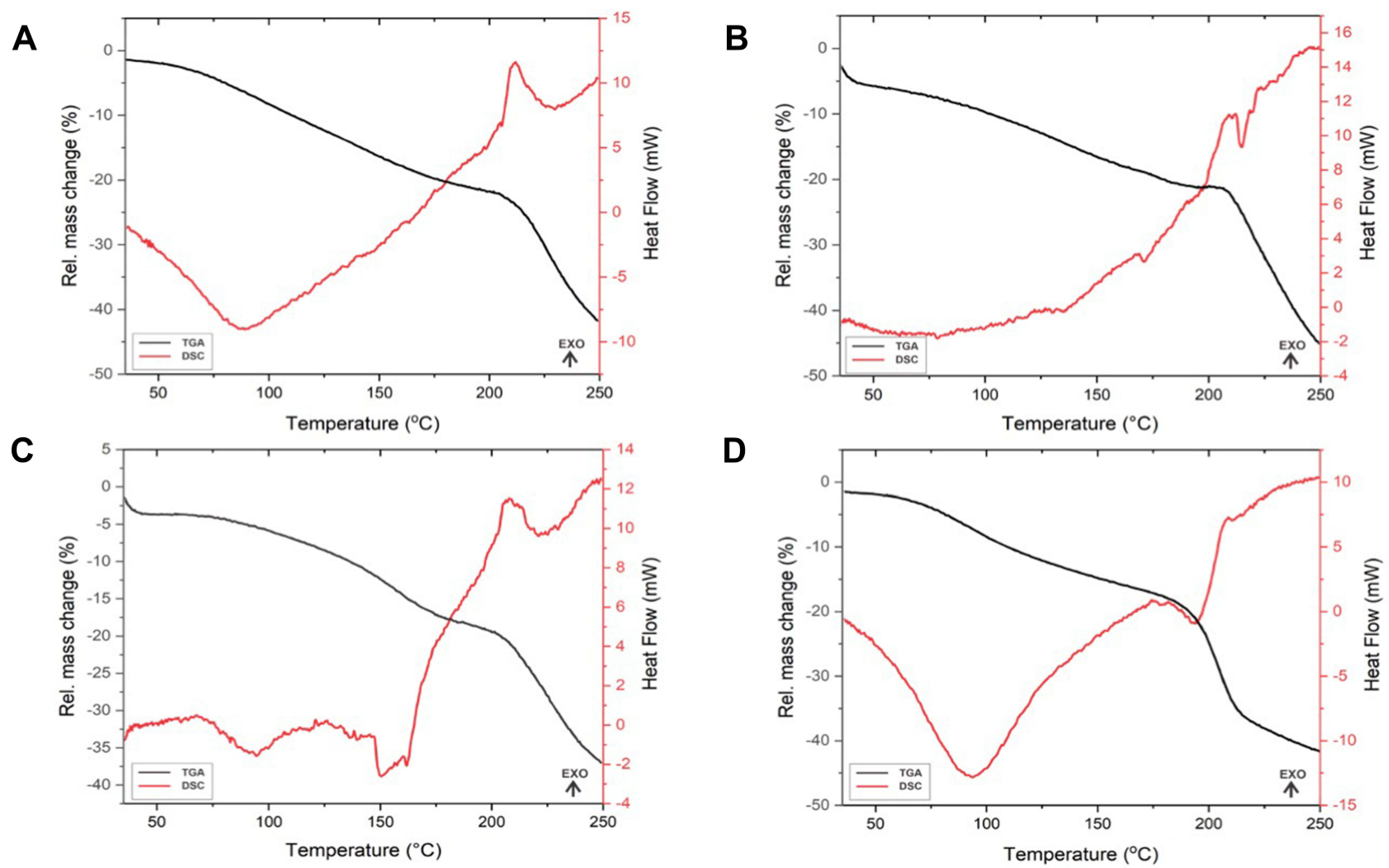

Figure 8 The TGA and DSC pattern of UHF formula: UHF5 (A), UHF7.5 (B), UHFI0 (C), Ulvan (D).

percentage in Figure 9. The inhibition of hydroxyl radicals by UHF10 was in the range of 50.16-97.4\%, UHF7.5 was in the range of $46.92-84.38 \%$, while UHF5 was in the range of 38.11-81.21\%. This inhibitory ability will help the hydrogel film function later in its application as a wound dressing. Previous studies by some researchers indicated that the presence of glucuronic acid, hydroxyl, and sulfated groups in Ulvan structure is reported to enhance the polymer chelating ability and the antioxidant activity of Ulvan. ${ }^{55-57}$ The antioxidant effect is characterized by radical damping and metal plating. This activity was also reportedly responsible for the antiproliferative effects of Ulvan. ${ }^{58}$

Shanmugapriya et $\mathrm{al}^{59}$ have studied the hydrogel base of fucoidan/alginate/gellan gum for wound treatment. The study reports that the hydrogel has antioxidant activity at a concentration of $100 \mathrm{~g} / \mathrm{mL}$ resulting in \% DPPH scavenging at $\pm 90 \%$. Meanwhile, in in vivo wound healing study, even though the wound closure of hydrogels with active compounds showed better wound contraction than the hydrogel sample without active compounds, the hydrogel base of fucoidan/ alginate/gellan gum still can promote wound healing and showed faster wound closures compared with negative controls.

\section{Antimicrobial Activity}

The antimicrobial properties of the hydrogel film formula were tested against gram-positive and negative bacteria, namely Staphylococcus aureus, Pseudomonas aeruginosa, Escherichia coli, and Streptococcus epidermidis. The gramnegative bacteria (Pseudomonas aeruginosa, Escherichia coli) and gram-positive bacteria (Staphylococcus aureus, Streptococcus epidermidis) are chosen for this test because they are the major bacteria that can cause wound infections. ${ }^{60}$ All formulas showed activity against these bacteria, where the UHF10 formula showed the greatest activity compared to the other two formulas (UHF5 and UHF 7.5). As shown in Figure 10, the highest microbial inhibitory activity was seen in Staphylococcus aureus $(7-8 \mathrm{~mm})$ and the lowest in Escherichia coli (4.7-6.6 mm). The result indicated the diameter of the zone of inhibition increased with increasing ulvan concentration. Fair activity of these biopolymers has been predicted. In general, polysaccharides do not show high activity and so are usually combined with the incorporation of antimicrobial agents in their formulations. Still, the antibacterial properties of Ulvan in hydrogel film preparations are expected to help its function as a wound dressing material. The proposed antibacterial 


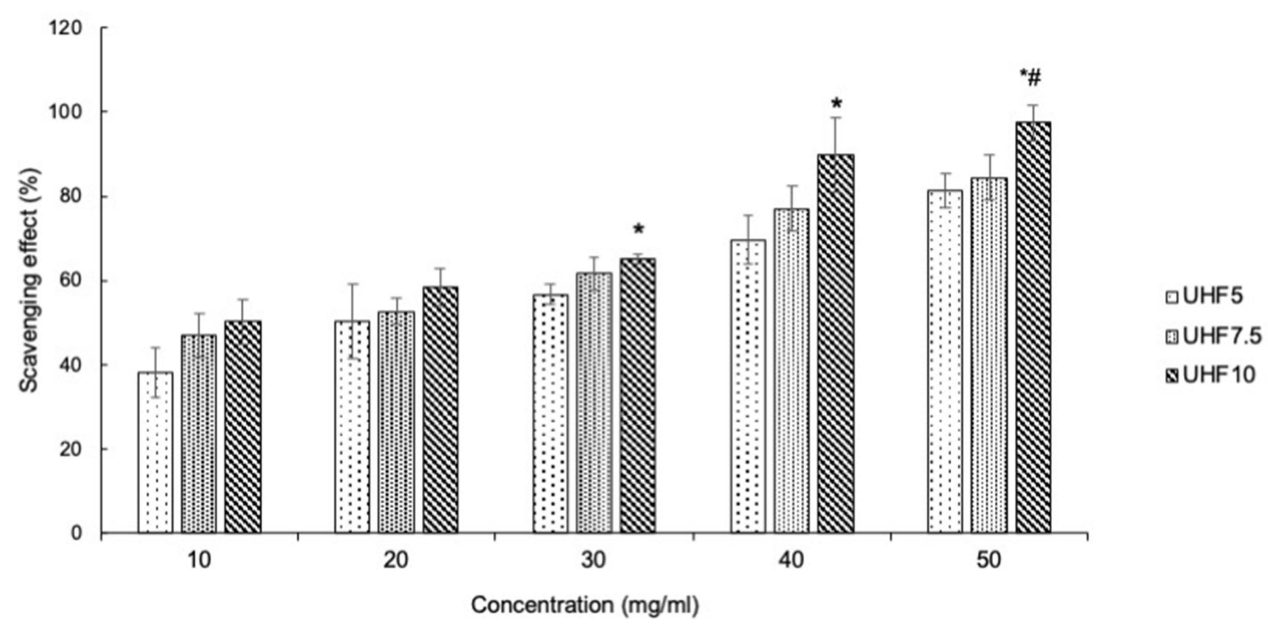

Figure 9 Hydroxyl radical scavenging activity of UHF. Each value represents the mean \pm SD of three experiments. ${ }^{*}<<0.05$, compared to the UHF 5 . ${ }^{\#}<0.05$, compared to the UHF 7.5 .

mechanism of marine polysaccharides is due to the glycoprotein receptor present on the cell surface polysaccharides that bind with compounds in the bacterial cell wall, cytoplasmic membrane, and DNA. This causes an increase in the permeability of the cytoplasmic membrane, protein leakage, and bacterial DNA binding. ${ }^{13}$

In comparison to the antimicrobial activity of Ulvan in UHF, the carrageenan film (without an antibacterial agent), did not show any activity against Streptococcus epidermidis and Escherichia coli. ${ }^{13}$ Likewise, the study by Hadisi et $\mathrm{al}^{61}$ showed that no bacterial activity against Staphylococcus aureus and Escherichia coli was observed for pure (without an antibacterial agent) gelatine (G)/oxidized starch (OST) nano-fibrous dressing. Pansara et $\mathrm{al}^{48}$ conducted a study using chitosan for wound healing, where the results showed that chitosan (without active compound) had an antimicrobial activity with an inhibitory diameter of $15 \mathrm{~mm}$, also showed a better wound healing activity during 21 days of observation compared to controls using sterile gauze.

\section{Conclusion}

Ulvan has been successfully developed into hydrogel film formulation by a simple physical mixing method. The preparation of Ulvan hydrogel films with various concentrations of Ulvan polysaccharides crosslinking with boric acid was comprehensively studied and concluded that the biomaterial in different concentrations in the hydrogel film formula gives a significant effect on some characteristics, such as swelling degree, WVTR, SEM image, TGA/DSC pattern and supported by the ability to reduce hydroxyl radicals and inhibit gram-positive and negative bacteria

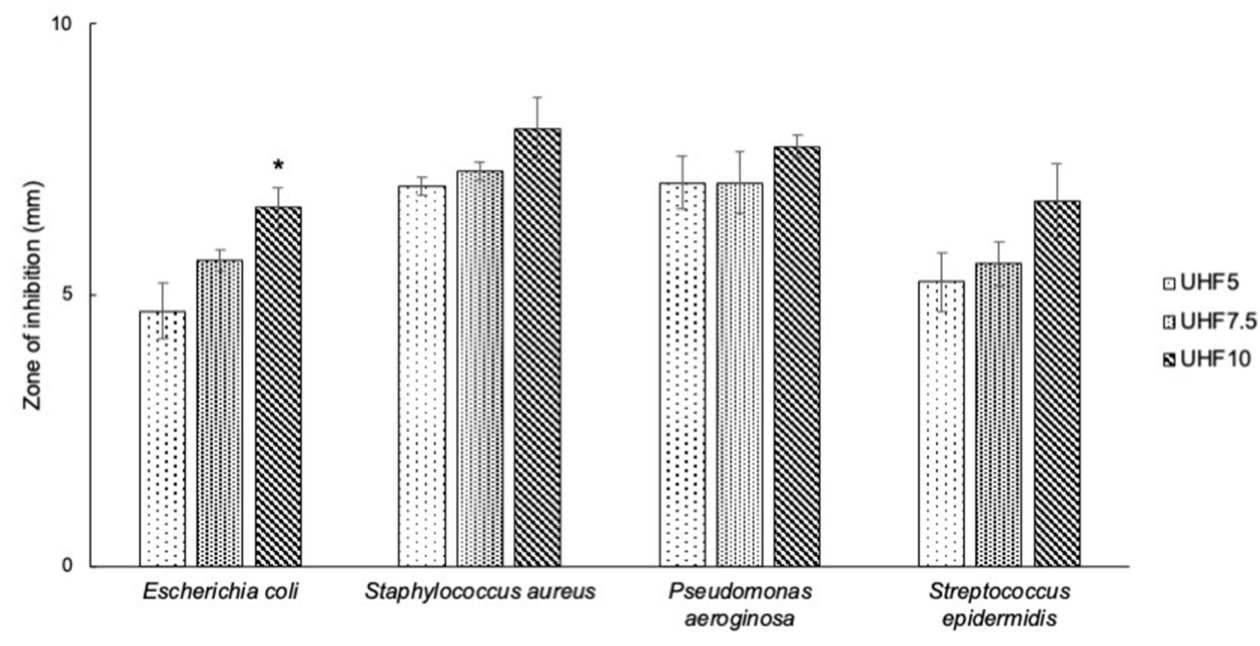

Figure 10 Antimicrobial activity of UHF. Each value represents the mean \pm SD of three experiments. ${ }^{*}<<0.05$, compared to the UHF 5 . 


\section{(Staphylococcus aureus, Pseudomonas aeruginosa,} Escherichia coli, and Streptococcus epidermidis). The presence of a chemical compound in this polysaccharide like glucuronic acid, rhamnose, sulfate, and hydroxyl groups contributes to those properties and activities (antioxidant and antimicrobial). Also, the addition of glycerol affected the characteristics of the films with different properties. In summary, we recommend the UHF10 as the most optimum formula compared to others based on the characteristics of the film preparation. The swelling degree of UHF10 showed increased swelling compared to the others as well as tensile strength and elongation, which are 2.62 $\mathrm{N} / \mathrm{mm}^{2}$ and $17.66 \%$, respectively. The moisture content and WVTR values are $18.4 \%$ and $1856 \mathrm{~g} / \mathrm{m}^{2} / 24 \mathrm{~h}$, respectively. Meanwhile, the SEM image shows a porous structure. Moreover, UHF10 shows higher antioxidant and antimicrobial activity than the other formula. These properties indicate that UHF10 has advantages, as it could absorb the wound fluid to prevent the wound bed from an accumulation of exudates. Even so, it can maintain a moist environment over the wound bed. Furthermore, with the support of antimicrobial and antioxidant properties, the ulvan hydrogel films prepared in this study are recommended to have high potential as new ideal wounddressing materials.

\section{Acknowledgments}

The authors are thankful to the Ministry of Education and Culture, the Republic of Indonesia, via the grant scheme of Hibah Penelitian Disertasi Doktor with number 1207/ UN6.3.1/PT.00/2021 for the financial support.

\section{Disclosure}

In this work, the authors declare no conflicts of interest.

\section{References}

1. Tran TTV, Truong HB, Tran NHV, et al. Structure, conformation in aqueous solution and antimicrobial activity of ulvan extracted from green seaweed Ulva reticulata. Nat Prod Res. 2018;32(19):2291-2296. doi:10.1080/14786419.2017.1408098

2. Zehlila A, Schaumann A, Mlouka AB, et al. Glioprotective effect of Ulva rigida extract against UVB cellular damages. Algal Res. 2017;23:203-215. doi:10.1016/j.algal.2017.02.001

3. de Araújo IWF, Rodrigues JAG, Quinderé ALG, et al. Analgesic and anti-inflammatory actions on bradykinin route of a polysulfated fraction from alga Ulva lactuca. Int J Biol Macromol. 2016;92:820-830. doi:10.1016/j.ijbiomac.2016.07.094

4. Paulert RJ, Smania Stadnik MJ, Pizzolatti MG. Antimicrobial properties of extracts from the green seaweed Ulva fasciata Delile against pathogenic bacteria and fungi. Arch Hydrobiol Suppl Algol Stud. 2007;123(1):123-130. doi:10.1127/1864-1318/2007/0123-0123
5. Amin HH. Ulvan as A new trend in agriculture, food processing and medicine. Asian J Fish Aquat Res. 2020;6(4):47-54. doi:10.9734/ ajfar/2020/v6i430105

6. Peasura N, Laohakunjit N, Kerdchoechuen O, Wanlapa S. Characteristics and antioxidant of Ulva intestinalis sulphated polysaccharides extracted with different solvents. Int J Biol Macromol. 2015;81:912-919. doi:10.1016/j.ijbiomac.2015.09.030

7. Li J, Chi Z, Yu L, Jiang F, Liu C. Sulfated modification, characterization, and antioxidant and moisture absorption/retention activities of a soluble neutral polysaccharide from Enteromorpha prolifera. Int J Biol Macromol. 2017;105:1544-1553. doi:10.1016/j.ijbiomac.2017.03.157

8. Zhao R, Liang H, Clarke E, Jackson C, Xue M. Inflammation in chronic wounds. Int J Mol Sci. 2016;17(12):2085-2099. doi:10.3390/ ijms 17122085

9. Percival SL, McCarty SM, Lipsky B. Biofilms and wounds: an overview of the evidence. Adv Wound Care. 2015;4(7):373-381. doi:10.1089/wound.2014.0557

10. Muntimadugu E, Ickowicz DE, Domb AJ, Khan W. Polysaccharide biomaterials. Isr J Chem. 2013;53(9-10):787-794. doi:10.1002/ ijch.201300062

11. Toskas G, Heinemann S, Heinemann C, et al. Ulvan and ulvan/ chitosan polyelectrolyte nanofibrous membranes as a potential substrate material for the cultivation of osteoblasts. Carbohydr Polym. 2012;89(3):997-1002. doi:10.1016/j.carbpol.2012.04.045

12. Alves A, Sousa RA, Reis RL. Processing of degradable ulvan 3D porous structures for biomedical applications. J Biomed Mater Res Part A. 2013;101 A(4):998-1006. doi:10.1002/jbm.a.34403

13. Jaiswal L, Shankar S, Rhim J-W. Carrageenan-based functional hydrogel film reinforced with sulfur nanoparticles and grapefruit seed extract for wound healing application. Carbohydr Polym. 2019;224:115191. doi:10.1016/j.carbpol.2019.115191

14. Koga AY, Pereira AV, Lipinski LCO. Evaluation of wound healing effect of alginate films containin g Aloe vera (Aloe barbadensis Miller) gel. J Biomater Appl. 2018;32(9):1212-1221. doi:10.1177/ 0885328218754615

15. Picone P, Sabatino MA, Ajovalasit A, Giacomazza D, Dispenza C, Di Carlo M. Biocompatibility, hemocompatibility and antimicrobial properties of xyloglucan-based hydrogel film for wound healing application. Int J Biol Macromol. 2019;121:784-795. doi:10.1016/j. ijbiomac.2018.10.078

16. Lee YE, Kim H, Seo C, et al. Marine polysaccharides: therapeutic efficacy and biomedical applications. Arch Pharm Res. 2017;40 (9):1006-1020. doi:10.1007/s12272-017-0958-2

17. Howell SNG, Sullivan BL. Seaweeds. Offshore Sea Life ID Guid. 2015;31. doi:10.1515/9781400874033-011

18. Ferdouse F, Holdt SL, Smith R, Murúa P, Yang Z. The global status of seaweed production, trade and utilization. FAO Globefish Res Program. 2018;124:120.

19. Dash M, Samal SK, Bartoli C, et al. Biofunctionalization of Ulvan scaffolds for bone tissue engineering. ACS Appl Mater Interfaces. 2014;6(5):3211-3218. doi:10.1021/am404912c

20. Morelli A, Chiellini F. Ulvan as a new type of biomaterial from renewable resources: functionalization and hydrogel preparation. Macromol Chem Phys. 2010;211(7):821-832. doi:10.1002/ macp. 200900562

21. Sulastri E, Lesmana R, Zubair S, Elamin KM, Wathoni N. Review and its biomedical applications. Chem Pharm Bull. 2021;69 (5):432-443. doi:10.1248/cpb.c20-00763

22. Chen X, Yue Z, Winberg PC, et al. Development of rhamnose-rich hydrogels based on sulfated xylorhamno-uronic acid toward wound healing applications. Biomater Sci. 2019;7(8):3497-3509. doi: $10.1039 / \mathrm{c} 9 \mathrm{bm} 00480 \mathrm{~g}$

23. Yaich H, Garna H, Besbes S, et al. Impact of extraction procedures on the chemical, rheological and textural properties of ulvan from Ulva lactuca of Tunisia coast. Food Hydrocoll. 2014;40(2014):53-63. doi:10.1016/j.foodhyd.2014.02.002 
24. Hernández-Garibay E, Zertuche-González JA, Pacheco-Ruíz I. Isolation and chemical characterization of algal polysaccharides from the green seaweed Ulva clathrata (Roth) C. Agardh. $J$ Appl Phycol. 2011;23(3):537-542. doi:10.1007/s10811-010-9629-0

25. Wahlström N, Nylander F, Malmhäll-Bah E, et al. Composition and structure of cell wall ulvans recovered from Ulva spp. along the Swedish west coast. Carbohydr Polym. 2020;233 (January):115852-115861. doi:10.1016/j.carbpol.2020.115852

26. Cerdan D, Grillon C, Monsigny M, Redziniak G, Kieda C. Human keratinocyte membrane lectins: characterization and modulation of their expression by cytokines. Biol Cell. 1991;73(1):35-42. doi:10.1016/0248-4900(91)90006-9

27. Andrès E, Molinari J, Péterszegi G, et al. Pharmacological properties of rhamnose-rich polysaccharides, potential interest in age-dependent alterations of connectives tissues. Pathol Biol. 2006;54(7):420-425. doi:10.1016/j.patbio.2006.07.004

28. Faury G, Ruszova E, Molinari J, et al. The $\alpha$-1-Rhamnose recognizing lectin site of human dermal fibroblasts functions as a signal transducer: modulation of $\mathrm{Ca} 2+$ fluxes and gene expression. Biochim Biophys Acta (BBA)-General Subj. 2008;1780(12):1388-1394. doi:10.1016/j.bbagen.2008.07.008

29. Lahaye M, Cimadevilla EAC, Kuhlenkamp R, Quemener B, Lognoné V, Dion P. Chemical composition and 13C NMR spectroscopic characterisation of ulvans from Ulva (Ulvales, Chlorophyta). J Appl Phycol. 1999;11(1):1-7. doi:10.1023/A:1008063600071

30. Quemener B, Lahaye M, Bobin-Dubigeon C. Sugar determination in ulvans by a chemical-enzymatic method coupled to high performance anion exchange chromatography. J Appl Phycol. 1997;9(2):179-188. doi:10.1023/A:1007971023478

31. Hirose K, Sasatsu M, Toraishi T, Onishi H. Novel xyloglucan sheet for the treatment of deep wounds: preparation, physicochemical characteristics, and in vivo healing effects. Biol Pharm Bull. 2019;42(8):1409-1414. doi:10.1248/bpb.b18-00764

32. Lahaye M, Axelos MAV. Gelling properties of water-soluble polysaccharides from proliferating marine green seaweeds (Ulva spp.) Carbohydr Polym. 1993;22(4):261-265. doi:10.1016/0144-8617(93) 90129-R

33. Lahaye M, Brunel M, Bonnin E. Fine chemical structure analysis of oligosaccharides produced by an ulvan-lyase degradation of the water-soluble cell-wall polysaccharides from Ulua sp. (Ulvales, Chlorophyta). Carbohydr Res. 1997;304(3-4):325-333. doi:10.1016/S0008-6215(97)00270-X

34. Hu W, Wang Z, Xiao Y, Zhang S, Wang J. Advances in crosslinking strategies of biomedical hydrogels. Biomater Sci. 2019;7(3):843-855. doi:10.1039/c8bm01246f

35. Jiang F, Chi Z, Ding Y, et al. Wound dressing hydrogel of enteromorpha prolifera polysaccharide-polyacrylamide composite: a facile transformation of marine blooming into biomedical material. ACS Appl Mater Interfaces. 2021;13(12):14530-14542. doi:10.1021/ acsami.0c21543

36. Suderman N, Isa MIN, Sarbon NM. The effect of plasticizers on the functional properties of biodegradable gelatin-based film: a review. Food Biosci. 2018;24:111-119. doi:10.1016/j.fbio.2018.06.006

37. Jia P, Xia H, Tang K, Zhou Y. Plasticizers derived from biomass resources: a short review. Polymers. 2018;10(12):1303. doi:10.3390/ polym 10121303

38. Khames A. Hexyl alginate derivative, an amphiphilic innovative buccal film-forming material of promising mechanical and release characteristics for the improvement of repaglinide bioavailability. Drug Des Devel Ther. 2019;13:925-940. doi:10.2147/DDDT. S196425

39. Nordin N, Othman SH, Rashid SA, Basha RK. Effects of glycerol and thymol on physical, mechanical, and thermal properties of corn starch films. Food Hydrocoll. 2020;106:105884. doi:10.1016/j. foodhyd.2020.105884
40. Zhang P, Zhao Y, Shi Q. Characterization of a novel edible film based on gum ghatti: effect of plasticizer type and concentration. Carbohydr Polym. 2016;153:345-355. doi:10.1016/j.carbpol.20 16.07.082

41. Liu F, Sen CB, Avena-Bustillos RJ, et al. Study of combined effects of glycerol and transglutaminase on properties of gelatin films. Food Hydrocoll. 2017;65:1-9. doi:10.1016/j.foodhyd.2016.10.004

42. Alves A, Caridade SG, Mano JF, Sousa RA, Reis RL. Extraction and physico-chemical characterization of a versatile biodegradable polysaccharide obtained from green algae. Carbohydr Res. 2010;345 (15):2194-2200. doi:10.1016/j.carres.2010.07.039

43. Costa C, Alves A, Pinto PR, et al. Characterization of ulvan extracts to assess the effect of different steps in the extraction procedure. Carbohydr Polym. 2012;88(2):537-546. doi:10.1016/j.carbpol.20 11.12.041

44. D638-14 ASTM. Standard test method for tensile properties of plastics. ASTM Int. 2015;1-17. doi:10.1520/D0638-14.1

45. Xu RB, Yang X, Wang J, et al. Chemical composition and antioxidant activities of three polysaccharide fractions from pine cones. Int $J \mathrm{Mol}$ Sci. 2012;13(11):14262-14277. doi:10.3390/ijms131114262

46. Rezvani E, Schleining G, Sumen G, Taherian AR. Assessment of physical and mechanical properties of sodium caseinate and stearic acid based film-forming emulsions and edible films. J Food Eng. 2013;116(2):598-605. doi:10.1016/j.jfoodeng.2012.12.039

47. Rezvanian M, Ahmad N, Mohd Amin MCI, Ng SF. Optimization, characterization, and in vitro assessment of alginate-pectin ionic cross-linked hydrogel film for wound dressing applications. Int J Biol Macromol. 2017;97:131-140. doi:10.1016/j.ijbiomac.20 16.12.079

48. Pansara C, Mishra R, Mehta T, Parikh A, Garg S. Formulation of chitosan stabilized silver nanoparticle-containing wound healing film: in vitro and in vivo characterization. J Pharm Sci. 2020;109 (7):2196-2205. doi:10.1016/j.xphs.2020.03.028

49. Üstündağ Okur N, Hökenek N, Okur ME, et al. An alternative approach to wound healing field; new composite films from natural polymers for mupirocin dermal delivery. Saudi Pharm J. 2019;27 (5):738-752. doi:10.1016/j.jsps.2019.04.010

50. Tziveleka LA, Sapalidis A, Kikionis S, et al. Hybrid sponge-like scaffolds based on ulvan and gelatin: design, characterization and evaluation of their potential use in bone tissue engineering. Materials. 2020;13(7):1-20. doi:10.3390/ma13071763

51. Kikionis S, Ioannou E, Toskas G, Roussis V. Electrospun biocomposite nanofibers of ulvan/PCL and ulvan/PEO. J Appl Polym Sci. 2015;132(26):1-5. doi:10.1002/app.42153

52. Tian H, Yin X, Zeng Q, Zhu L, Chen J. Isolation, structure, and surfactant properties of polysaccharides from Ulva lactuca L. from South China Sea. Int J Biol Macromol. 2015;79:577-582. doi:10.1016/j.ijbiomac.2015.05.031

53. Dash M, Samal SK, Morelli A, et al. Ulvan-chitosan polyelectrolyte complexes as matrices for enzyme induced biomimetic mineralization. Carbohydr Polym. 2018;182:254-264. doi:10.1016/j. carbpol.2017.11.016

54. Pereira R, Carvalho A, Vaz DC, Gil MH, Mendes A, Bártolo P. Development of novel alginate based hydrogel films for wound healing applications. Int J Biol Macromol. 2013;52(1):221-230. doi:10.1016/j.ijbiomac.2012.09.031

55. Ganesan AR, Shanmugam M, Bhat R. Producing novel edible films from semi refined carrageenan (SRC) and ulvan polysaccharides for potential food applications. Int $J$ Biol Macromol. 2018;112:1164-1170. doi:10.1016/j.ijbiomac.2018.02.089

56. Abou El Azm N, Fleita D, Rifaat D, Mpingirika EZ, Amleh E, ElSayed,MMH. Production of bioactive compounds from the sulfated polysaccharides extracts of ulva lactuca: post-extraction enzymatic hydrolysis followed by ion-exchange chromatographic fractionation. Molecules. 2019;24(11):2132-2149. doi:10.3390/molecules24112132 
57. Li B, Liu S, Xing R, et al. Degradation of sulfated polysaccharides from Enteromorpha prolifera and their antioxidant activities. Carbohydr Polym. 2013;92(2):1991-1996. doi:10.1016/j.carbpol.20 12.11 .088

58. Abd El-Baky HH, El Baz FK, El-Baroty GS. Evaluation of marine alga Ulva Lactuca L. as a source of natural preservative ingredient. Am Eurasian J Agric Env Sci. 2008;3(3):434-444.

59. Shanmugapriya K, Kim H, Kang HW. Fucoidan-loaded hydrogels facilitates wound healing using photodynamic therapy by in vitro and in vivo evaluation. Carbohydr Polym. 2020;247(January):116624. doi:10.1016/j.carbpol.2020.116624
60. Wang Y, Beekman J, Hew J, et al. Burn injury: challenges and advances in burn wound healing, infection, pain and scarring. $A d v$ Drug Deliv Rev. 2018;123:3-17. doi:10.1016/j.addr.2017.09.018

61. Hadisi Z, Nourmohammadi J, Nassiri SM. The antibacterial and anti-inflammatory investigation of Lawsonia Inermis-gelatin-starch nano-fibrous dressing in burn wound. Int $J$ Biol Macromol. 2018;107:2008-2019. doi:10.1016/j.ijbiomac.2017.10.061

\section{Publish your work in this journal}

Drug Design, Development and Therapy is an international, peerreviewed open-access journal that spans the spectrum of drug design and development through to clinical applications. Clinical outcomes, patient safety, and programs for the development and effective, safe, and sustained use of medicines are a feature of the journal, which has also been accepted for indexing on PubMed Central. The manuscript management system is completely online and includes a very quick and fair peer-review system, which is all easy to use. Visit http://www. dovepress.com/testimonials.php to read real quotes from published authors. 